\title{
Editor's Column: Collateral Damage
}

It is the photographs that give one the vivid realization of what actually took place. Words don't do it. The words that there were abuses, that it was cruel, that it was inhumane, all of which is true, that it was blatant, you read that and it's one thing. You see the photographs, and you get a sense of it, and you cannot help but be outraged.

—Donald Rumsfeld

N AN INTERVIEW FOLLOWING HIS 7 MAY 2004 TESTIMONY to the Senate Armed Services Committee, Donald Rumsfeld, the

United States secretary of defense, admitted knowing about abuses at the Abu Ghraib prison since they were first exposed in January. He also knew of the existence of photographs documenting the abuses, but he had not studied the images until shortly before they were shown to the public during the first week of May. In asserting that "[i]t is the photographs that give one the vivid realization of what actually took place" and that "[w]ords don't do it," Rumsfeld expressed, and even surpassed, one of the prime clichés of our time, that a picture is worth a thousand words. Before the power of visual images, the subject has an uncontrollable emotional response: "you cannot help but be outraged."

No wonder, then, that images from the Iraq war have been so strictly controlled by the government; no wonder that their revelation-whether they are images of coffins, of wounded soldiers, of scenes of torture perpetrated by or against Americans-has been so explosive. General Richard B. Myers, chairman of the Joint Chiefs of Staff, even went so far as to ask CBS's Sixty Minutes II to delay showing the photographs of prison abuse to the public lest their dissemination do harm to the troops abroad, and throughout May and June of this year pictures from Abu Ghraib were printed and distributed slowly and with an unusual degree of cautionary

(C) 2004 BY THE MODERN LANGUAGE ASSOCIATION OF AMERICA 
framing. ${ }^{2}$ Congress members first saw hundreds of images in closed, tightly protected settings (Hulse and Stolberg). They described them to the press but were prohibited from showing them to the public. The ethics of revelation was debated among commentators and politicians weighing freedom of information versus the victims' right to privacy. ${ }^{3}$ But clearly more was at stake. It is $\mathrm{OK}$, it seems, to read descriptions of photographs; it may not be OK to look. Even as the government tried to control access to images, however, fearing their political fallout - their "collateral damage"-they surfaced and were disseminated on the Internet.

In the fall of 2001, immediately following the attacks on the World Trade Center, Mayor Rudolph Giuliani of New York banned cameras from the area around ground zero; photographs of persons falling or jumping from the World Trade Center towers, such as the one by Richard Drew, appeared in newspapers around the world on 12 September only quickly to be censored by these same papers (Junod). The second Iraq war began as a spectacle staged for the American television viewer, with its "embedded" journalists and photographers, but as soon as Americans were being wounded and killed in significant numbers, the dissemination of images was strictly controlled. American and European photographers have been harassed and detained by the United States military on several occasions when they attempted to cover the continuing bloodshed in Iraq (Cole). It took months and a journalistic request under the Freedom of Information Act for the public to be allowed to view photographs of coffins, and, ironically, it took Garry Trudeau and his comic strip "Doonesbury" to generate powerful empathy with the wounded soldiers, who so far have remained largely absent from mainstream media. Perhaps Trudeau's character BD, an enthusiastic soldier, had to have his leg amputated because the wounds had until then been made invisible in the news pages of the paper.

The government's fearful, even paranoid, treatment of images echoes sentiments frequently expressed by some of us who work with words in the academy - that in the current media age our students (never mind our public officials) have lost their verbal literacy and have given themselves over to an overwhelmingly dominant, uncontrollable visuality that impairs thought. But the contributions to this issue of PMLA, interrogating visuality and visual-verbal intersections in literature, film, performance, and the visual arts, reveal to me that our field has already moved beyond this anxiety. The essays and the position papers on "literary studies and the visual arts" for The Changing Profession articulate how the methods of interpretation emerging from the fields of literary studies, film studies, and visual culture illuminate one another, leading to richer, deeper insights into visual, verbal, and performative texts and into their interrelations. Whether addressing intertextuality and cinema in Oscar Wilde and Billy Wilder (Brown), oral and visual testimony in Jean Rouch and Edgar Morin's Chronicle of a Summer (Rothberg), literary and artistic cubism in Ralph Ellison and Romare Bearden (Yukins), conflicts over spectatorship on the eighteenth-century Dublin stage (Harris), or the use of masquerade in the formation of American national identity (Smith-Rosenberg), the essays in this issue gesture toward a wordimage conjunction that would replace the wordimage opposition that has dominated literary and visual studies for decades. These essays, especially read in relation to the position papers in the special feature on literary studies and the visual arts, also show that there is a great deal yet to say about words and images and their expressivity in specific cultural and historical contexts. Having worked on both literary and visual texts for the last two decades, I was pleased to assemble an issue that would focus some of these questions, and I looked forward to introducing them in theoretical terms in this column. Beginning to write the column in May of 2004, however, I was faced with a very particular set of images and the words generated about them in the media. And I found that the interdisciplinary direc- 
tion many of us have taken in our field, toward film, performance, and visual arts, toward sound and digital media, together with the sensitivity to language in which we have been trained, not only enables but compels us to address the interaction of words and images in the political arena in a time of war.

A sustained discussion of words and images, of reading and looking, seems especially urgent at a moment when trauma is instrumentalized as an alibi for censorship. The relation of visuality to the experience and the transmission of personal and cultural trauma - trauma that may be unspeakable but may be communicated viscerally and emotionally through the alternative cognitive structures of the visual-is a significant preoccupation of the essays in this issue.

Even while some of the authors in this issue, like Tobin Siebers, continue to perceive linguistic prejudices underlying our critical methods and our language about images, the contributors also affirm the extraordinary power and what Siebers terms the "excessive expressivity" of visual images. Mieke Bal, Mary Ann Caws, and Siebers highlight the detail as the site where we enter and, indeed, "read" images. Attention to the visual detail singles out the untranslatable power of visuality and its alternative, nonverbal, structures of meaning: "My attention was systematically arrested by the detail that seems out of place, the contradiction that tears open the work, the monstrous element that reveals flaws and disparities and, because it provokes astonishment, offers never-ending possibilities for the understanding of these works," writes Bal. For Siebers, the isolated detail is a sign both of materiality and of disability: "To detail is to cut, and many details preserve this primordial association with the slicing, abrading, or disturbing of a surface, whether the disruption involves flesh or nonorganic skin.... What [the detail] pictures is a certain excess that ... might be called disability. ..." In the word-image relation, Siebers maintains, the image is akin to the disabled body, and it elicits similar prejudice and disparagement.
Roland Barthes's notion of the "punctum" in his Camera Lucida, an enabling trope for several contributors to these pages, allows us to imagine the "excessive expressivity of images" as a form of wounding. Barthes describes his relation to photographs, in particular, as an opening to the piercing quality of details that shock and disturb, grab, puncture and wound (41-59). "The image may teach nothing," Siebers writes, "but it does open wounds." And Peggy Phelan cites Samuel Beckett's description of seeing: "For it is not at all about a sudden awareness, but a sudden visual grasp, a sudden shot of the eye. Just that."

If, as these essays suggest, seeing is a form of wounding and being wounded, a "shot of the eye," then to see, to be a spectator, is to respond through body and affect, as well as through the intellect. How do these forms of response determine the use to which images are put? Indeed, in the context of the war in Iraq, visual images function not just as evidence of violence but also-and herein lies their collateral damageas actual instruments of torture and humiliation. It is no wonder that Iraqi insurgents and American prison guards knew how to exploit images as powerful weapons of intimidation by staging some of their own brutal acts for still and video cameras. Torturers also know about the "excessive expressivity of images." They may know that potential victims who confront photographs of tortured bodies will not merely look at these as representations of trauma suffered by others but also experience the trauma affectively and viscerally, in their own bodies. Using Charlotte Delbo's notion of "sense memory"- the memory residing in the body of the Auschwitz survivor and remaining split off from the "ordinary memory" that produces narratives about life in the camp - the art historian Jill Bennett argues that although "words can be put into the service of sense memory, vision has a very different relationship to affective experience, experience which whilst it cannot be spoken as it is felt, may register visually. The eye can often function 
as a mute witness through which events register as eidetic memory images imprinted with sensation" (84). But if torture scenes were staged and photographed to intimidate and humiliate new potential victims through the workings of sense memory, they have the same effect on spectators outside this specific context, who thus become unintended victims. The workings of sense memory imprinted on the body through vision have produced an explosive impact on the world stage, uniting rather than dividing victims, perpetrators, and bystanders in their embodied subjectivity. The wounding effect of images blurs the boundaries between these positions: spectators and even perpetrators experience themselves as victims, however unintended, of the images themselves or of their unplanned circulation.

Before images of violence and torture, we find ourselves like Beckett's Didi and Gogo, as evoked by Phelan, faced with "the impossibility of seeing and the impossibility of not looking." We have previously seen images of atrocity made by perpetrators such as the Abu Ghraib prison photos: pictures of lynchings showing not just victims and executioners but also cheering crowds of onlookers; photographs by the Wehrmacht and the SS of their own crimes in World War II, mailed home as tourist snapshots; violent and coerced pornographic images disseminated for the international scopophilic viewer (Brison). Before $9 / 11$, theorists of visuality feared that overpublication of atrocity images would inure the public to their effect and would diminish their power to shock. Commentators warned that, in the society of the spectacle, images of war and atrocity and images from popular films and television programs simulating war, violence, and disaster would meld and produce compassion fatigue and even indifference. Photographs and other still images are flat and two-dimensional, limited by their frames. They can contain and domesticate atrocity, making it manageable, comprehensible. They quickly assume symbolic meaning and so remove themselves from the real (Zelizer 10). In the work of cultural memory, their multiplicity may be overwhelming, and thus the archive of atrocity photos is quickly limited to just a few emblematic images repeated over and over. In their iconicity and repetition, they may lose their power to wound.

Recently, however, even Susan Sontag, a harsh critic of photography, has changed her mind about the medium. "I am not so sure now," she writes in Regarding the Pain of Others: "What is the evidence that photographs have a diminishing impact, that our culture of spectatorship neutralizes the moral force of photographs of atrocity?" (105). At the same time, Sontag chastises us for succumbing to the seductiveness of war, for our ability to look away, to close our eyes and turn the page. Vision is both piercing and distant for her. The pain of others remains so tragically remote that, as she emphasized in the New York Times Magazine in May 2004, perpetrators are "posing, gloating, over their helpless captives" ("Regarding" 2627 ) and themselves distributing images of their crimes to family and friends. The same image can be entertaining for one set of viewers and traumatic for another.

What kind of visual-verbal literacy can respond to the needs of the present moment? ${ }^{4}$ The analyses of words and images, reading and spectatorship in this issue contain suggestions, as do the hybrid texts on which these articles are based. "You don't have to look," Gogo says to Didi. "You can't stop looking," Didi responds, characterizing our current position in relation to the power of visuality. Like Beckett's characters, we see but are unable to look and unable to transform the field of vision into insight and meaning - unable to articulate, in clear terms, the relation between images and words. Phelan speaks of Beckett's "biocularity," his reading of images as words, of words as images: "Seeing was always already a way of saying for Beckett, and so too was saying a way of seeing."

In the Shadow of No Towers, Art Spiegelman's reflections on $9 / 11$, from which the cover 
of this issue is borrowed, is both a manifestation of this kind of visual-verbal biocularity and a meditation on traumatic seeing. In the first of the ten comics pages making up In the Shadow of No Towers, Spiegelman asserts that "I live on the outskirts of ground zero and first saw it all live-unmediated." This is to distinguish his view from that of the comics characters on the upper part of the page, watching their television screen (and, presumably, the collapse of the towers), eyes bulging and hair standing on end. But when he draws his own experiences on the morning of 9/11 in Lower Manhattan on subsequent pages, Spiegelman admits to everything he did not, in fact, see. "He didn't actually see the first plane smash into the tower a few blocks South of his Soho home. . . They heard the crash behind them while heading North. He did see the face of a woman heading South ..." (2). The word-image "ROARRRRRRRR!!" almost covers the statement about not seeing, occluding it to the point of near illegibility. Not seeing becomes visible and even audible, as graphic as the absent towers. Words, images, and wordimages work together to enact the impossibility of seeing and the impossibility of not looking.

Through its comics form, In the Shadow of No Towers complicates any clear differentiations between word and image. With words always already functioning as images and images asking to be read as much as seen, comics are biocular texts par excellence. Asking us to read back and forth between images and words, comics reveal the visuality and thus the materiality of words and the discursivity and narrativity of images. But In the Shadow of No Towers, like its predecessor Maus, also performs an aesthetics of trauma: it is fragmentary, composed of small boxes that cannot contain the material, which exceeds their frames and the structure of the page. Architecturally mirroring the structure of the towers and thereby allowing us to keep them in view even as they collapse in front of our eyes, again and again, In the Shadow of No Towers operates on a number of levels at once.
Enabling reality and fantasy, historical and fictional figures, human and cartoon characters to coexist and morph into each other, it demands an extraordinarily complex response beyond just combining reading and looking. Comics highlight both the individual frames and the space between them, calling attention to the compulsion to transcend the frame in the act of seeing. They thus startlingly reveal the limited, obstructed vision that characterizes a historical moment ruled by trauma and censorship.

"I wanted to sort out the fragments of what I'd experienced from the media images that threatened to engulf what I actually saw," Spiegelman writes in his introduction to the book. "What I actually saw," he insists, was "burned into the inside of my eyelids," seared into his skull forever, and thus in No Towers those scenes are drawn as a set of photographs strewn across the page (4). At the moment of trauma, time stands still, images are frozen, like the glowing tower that is repeated over and over in the pages of Spiegelman's work. To see is to be wounded, seared, burned. Even as he insists on specifying what he "actually" saw, however, Spiegelman also admits to being "haunted now by the images he didn't witness" (No Towers 5), drawing, on the entire left side of one of the pages, a troubling image of a falling man based on the censored photograph by Richard Drew. Vision is faulty, mediated, unreliable, blocked. As Siebers writes, "The image may teach nothing, but it does open wounds." Those who witnessed the collapse of the towers and those who saw the photographs of the towers collapsing and the people jumping-many millions, in this moment of global witness - also became the victims of the attacks. The wounding by images was the collateral damage of the attacks on the World Trade Center. ${ }^{5}$

At the same time, Spiegelman also exposes the protective mechanisms that are deployed by the ways in which vision typically operates in our culture. "He saw the burning towers as he and his wife ran to Canal Street, toward the 


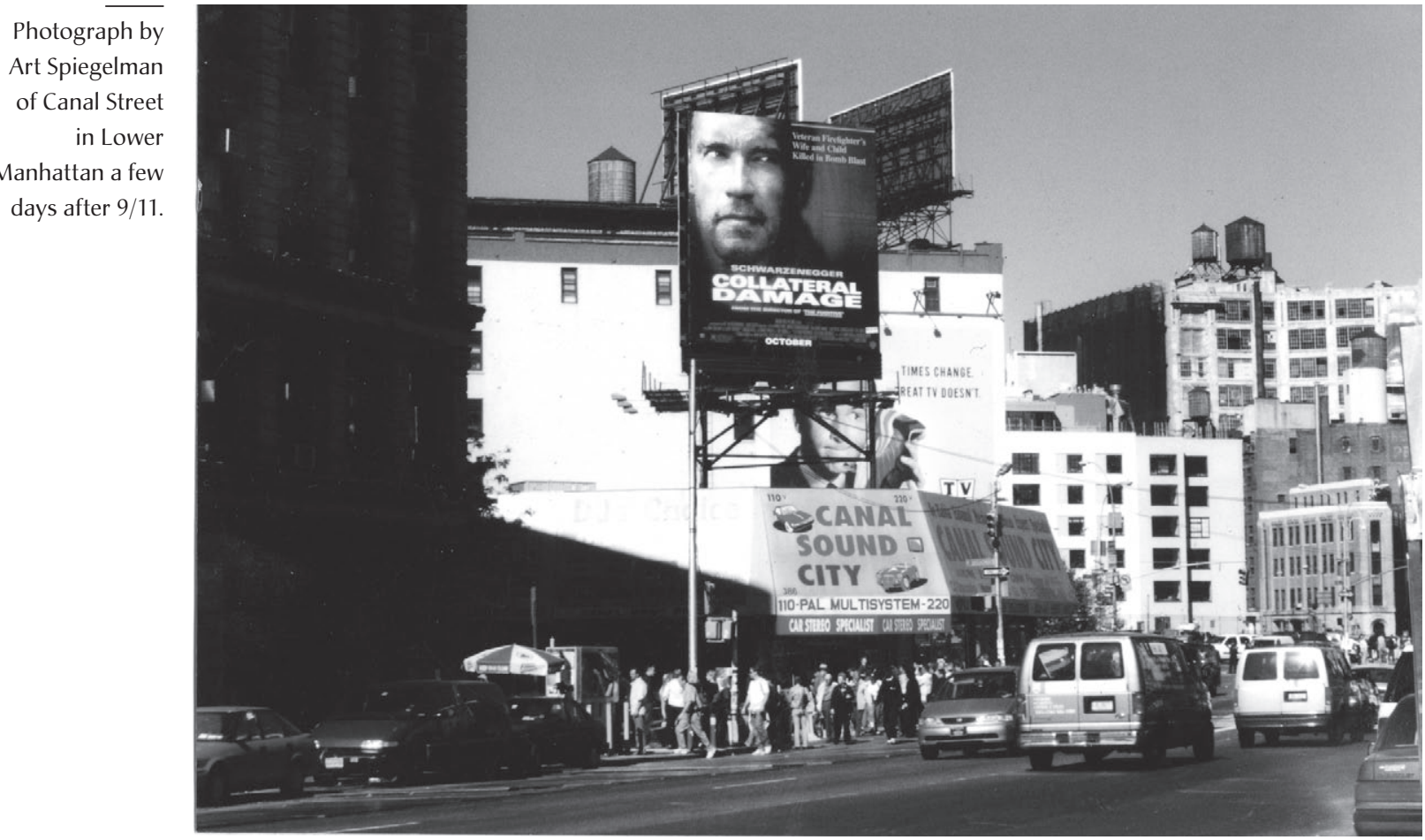

school ... but his view was obstructed as he ran up the next block. . . . He could only see smoke billowing behind a giant billboard. . . . It was for some dopey new Schwarzenegger movie about terrorism." The next panel is dominated by a giant poster for the film, Collateral Damage, with dark smoke billowing all around. The panel reads, "Oddly, in the aftermath of September 11th, some pundits insisted that Irony was Dead." The film Collateral Damage, advertised in September 2001, was deemed inappropriate after the attacks and was not released to theaters until several months later. But the giant poster obstructing the view of the burning towers itself exemplifies the movie's title, "collateral damage" - a euphemism for the destruction of people and property not directly targeted by the military. But in the context of 9/11 (and the wars that followed), "collateral damage" also describes both the cost of seeing the traumatic real and the costs of not being allowed to look.

Euphemism ("abuse" for torture, "collateral damage" for unintended killing or for undesirable political consequences) is the linguistic equivalent of obstructed, censored, vision. In another context, Diana Taylor has termed this obstruction "percepticide," "the self-blinding of the general population," the "fear, denial and tacit complicity" that bring a population "to see without being able to do." Taylor's term refers to the Argentinian "Dirty War" of the 1970s, which relied on another euphemism, "disappearance" for abduction, torture, and murder (123). Euphemism is also an assertion of the power and danger of language. And this is where the study of language and literature connects to the study of visual culture.

Media representations function like euphemisms to obstruct seeing, saying, and understanding. The collapsing towers on television looked just "like" the disaster movies to which we are habituated. Media representations shield us from the "excessive expressivity" of the visual to the point where, through the self-blinding of "percepticide," we can live with ourselves as we look without seeing, see without doing, understand without saying or writing. What, Spiegelman's text seems to ask, might enable us to see 
what we "actually" witness? How might we see beyond what Kaja Silverman, following Lacan, has termed "the given-to-be-seen" (175-85), beyond the ready-made tropes and clichéd images that frame our look, dominating the visual field and protecting us from trauma?

In the frames on Spiegelman's pages, words and images that in their media representation and repetition threaten to lose their wounding power reappear in newly alienated, and thus freshly powerful, form. In this work, Spiegelman mobilizes comics and the acts of seeing and reading they demand in an attempt to see beyond the given-to-be-seen and to say what cannot otherwise be said.

\section{Marianne Hirsch}

\section{NOTES}

${ }^{1}$ Shanker and Schmitt A1.

${ }^{2}$ As quoted in the New York Times, Myers said, "What I asked CBS News to do was to delay the release of the pictures given the current situation in Iraq, which was as bad as it had been since major combat ended, because I thought it would bring direct harm to our troops. It would kill our troops" (Shanker and Schmitt A1). Additional photos were first printed in the Washington Post on 21 May 2004, along with the testimonies of detainees. On that day, in a long online chat, Executive Editor Leonard Downie, Jr., explained the Post's decision to make the photos and documents, as well as related videos, available to the public.

${ }^{3}$ Carl Hulse and Sheryl Gay Stolberg write, "The explicit nature of the photographs left the lawmakers deeply conflicted over whether the images should be made public. Some who previously favored a public release said they had changed their minds and were swayed by remarks from military personnel that to do so would violate the prisoners' right to privacy and protection from humiliation under international law" (A1).

${ }^{4}$ I understand that the term visual literacy exhibits linguistic prejudices, and I use it not only because I don't know a better term and because it is commonly in use but also to make the point that the word-image conjunction to which the essays in this issue aspire will require that those who work in literary and in visual studies borrow from each other's conceptual and lexical registers.

${ }^{5}$ On trauma, collateral damage, and concomitant loss, see Kacandes.

\section{Works Cited}

Barthes, Roland. Camera Lucida: Reflections on Photography. Trans. Richard Howard. New York: Farrar, 1981.

Bennett, Jill. "The Aesthetics of Sense-Memory: Theorising Trauma through the Visual Arts." Trauma und Erinnerung, Trauma and Memory: Cross-Cultural Perspectives. Ed. Franz Kaltenbeck and Peter Weibel. Vienna: Passagen, 2000. 81-96.

Brison, Susan J. "Connect the Pixels: Fact and Fiction in a Pornographic World." Chronicle of Higher Education Review 4 June 2004: B10.

Cole, Juan. "We Are Losing the War over Pictures." History News Network. 3 May 2004. 20 July $2004<$ http://hnn .us/articles/4880.html >.

Downie, Leonard, Jr. "Iraq: New Abuse Details.” Washington Post 21 May 2004. 20 July $2004<$ http://www .washingtonpost.com/ac2/wp-dyn/A44952-2004May21>.

Hulse, Carl, and Sheryl Gay Stolberg. "The Struggle for Iraq: Congress; Lawmakers View Images from Iraq." New York Times 13 May 2004: A1+.

Junod, Tom. "The Falling Man.” Esquire 1 Sept. 2003: 176+.

Kacandes, Irene. "9/11/01 =1/27/01: The Changed Posttraumatic Self." Trauma at Home: After 9/11. Ed. Judith Greenberg. Lincoln: U of Nebraska P, 2003. 168-83.

Shanker, Thom, and Eric Schmitt. "Rumsfeld Accepts Blame and Offers Apology in Abuse." New York Times 8 May 2004: A1+.

Silverman, Kaja. The Threshold of the Visible World. New York: Routledge, 1996.

Sontag, Susan. Regarding the Pain of Others. New York: Farrar, 2003.

_. "Regarding the Torture of Others." New York Times Magazine 23 May 2004: 24+.

Spiegelman, Art. In the Shadow of No Towers. New York: Pantheon, 2004.

Taylor, Diana. Disappearing Acts: Spectacles of Gender and Nationalism in Argentina's "Dirty War." Durham: Duke UP, 1997.

Zelizer, Barbie. Remembering to Forget: Holocaust Memory through the Camera's Eye. Chicago: $\mathrm{U}$ of Chicago P, 1998 . 